\title{
The Use of Salvia macrosiphon and Lepidium sativum Linn. Seed Gums in Nanoencapsulation Processes: Improving Antioxidant Activity of Potato Skin Extract
}

\author{
Javad Tavakoli $\mathbb{D}^{1},{ }^{1}$ Habib Abbasi $\left(\mathbb{D},{ }^{2}\right.$ Aniseh Zarei Jelyani $\mathbb{D}^{3}{ }^{3}$ \\ and Amin Mousavi Khaneghah $\mathbb{1}^{4}$ \\ ${ }^{1}$ Department of Food Science and Technology, Faculty of Agriculture, Jahrom University, Jahrom, Iran \\ ${ }^{2}$ Department of Chemical Engineering, Jundi-Shapur University of Technology, Dezful, Iran \\ ${ }^{3}$ Department of Food and Drug, Shiraz University of Medical Science, Shiraz, Iran \\ ${ }^{4}$ Department of Food Science and Nutrition, Faculty of Food Engineering, University of Campinas (UNICAMP), Campinas, \\ São Paulo, Brazil
}

Correspondence should be addressed to Habib Abbasi; habbasi@jsu.ac.ir and Amin Mousavi Khaneghah; mousavi@unicamp.br Received 16 January 2021; Accepted 3 May 2021; Published 12 May 2021

Academic Editor: Antoni Szumny

Copyright @ 2021 Javad Tavakoli et al. This is an open access article distributed under the Creative Commons Attribution License, which permits unrestricted use, distribution, and reproduction in any medium, provided the original work is properly cited.

\begin{abstract}
In the present study, the effect of Salvia macrosiphon Seed Gum (SMSG) and Lepidium sativum Linn. Seed Gum (LSSG) as a coating agent on the properties of nanoencapsulated potato skin extract was studied. Moreover, the antioxidant effect of nanoencapsulated extract at a concentration of $1000 \mathrm{ppm}$ incorporated into soybean oil was evaluated. The Z-average size of the emulsions stabilized by SMSG; LSSG; and a complex (1:1) of SMSG and LSSG (CSL) was estimated as 160.2, 144.3, and 115.2 nm. The encapsulation efficiency of phenolic extracts in the powders formed by SMSG, LSSG, and CSL was $82.39,81.67$, and 93.6\% which declined to $45.28,48.22$, and $62.67 \%$ after storage for 40 days at $30^{\circ} \mathrm{C}$. The results indicated that the use of coating agents for encapsulation enhanced their antioxidant effect and compared with TBHQ and free extract that nanoencapsulated extract by CSL had the highest antioxidant activity followed by LSSG nanoencapsulated extract and SMSG nanoencapsulated extract.
\end{abstract}

\section{Introduction}

Agricultural products and crops are widely processed in the food industry. During food processing, parts of these products such as skin are separated as waste which can used to produce some value added compounds such as antioxidants [1]. Potato represents a major segment of the produce crop across the world, especially in developing countries, with well-known antihypertensive, antimicrobial, and anticancer properties [2]. While the functional properties of potato can be achieved by using both pulp and skin, the latter one is usually discarded. On the other hand, by-products are gaining much attention as a source of natural antioxidants [1]. Albishi et al. [3] has reported potato skin is a rich source of phenolic compounds with a desirable level of antioxidant activity. The most important phenolic compounds in potato skin included chlorogenic acid, caffeic acid, and ferulic acid.

Oxidation of lipids and oils has a significant impact on product shelf life because this reaction is accompanied by bad odor and reduction in nutritional value [4]. Moreover, it causes the formation of free radicals which resulted in some destructive impacts on live cells $[4,5]$. Through inhibiting free radicals, antioxidants play an important role in the reduction of oxidation rate and, hence, prevention of cardiovascular diseases and some types of cancer [6]. As recent evidence demonstrated the dangerous effects of synthetic antioxidants [7], several investigations have been conducted to introduce the natural antioxidants $[8,9]$, while the incorporation of plant-based antioxidant extracts in edible oils represents a major approach for further increasing in oxidative stability of the oils. The impact of natural antioxidants on oil oxidation 
can be limited due to their early degradation during long-term storage of the oils [10]. In this context, some techniques in the field of application of emulsion systems for improvement of antioxidants efficiency were introduced [11]. Among them, the encapsulation as a promising technique in the field of food and medicine industries (particularly nanocapsules with particle size ranging from $10-1000 \mathrm{~nm}$ ) offers the coating of the compounds by using some natural macromolecules while the corresponded antimicrobial and antioxidant properties and also their release control are improved [12, 13]. The release of compounds from the capsule is directly affected by their size; thus, nanoencapsulation can improve their bioavailability and release quality while compared with microencapsulation (particle size varies between 3 and $800 \mu \mathrm{m}$ ) $[12,14]$. It has been confirmed in many studies that nanoencapsulation can improve antioxidant properties of Beneh skin extract, date palm pit extract, and olive leaf extract by the formation of $\mathrm{W} / \mathrm{O} / \mathrm{W}$ double-layer multiple emulsions [15-17]. Various varieties of potato are also cultivated in Iran, the Ramus variety being famous among them, while there is no use of their skin, and past research has proven this part of the potato is a rich source of phenolic compounds. Also, the use of natural gums in the encapsulation process of active compounds such as phenols has been carried out in various research studies $[12,15]$. Two of the gums that are widely available in Iran are Salvia macrosiphon and Lepidium sativum Linn. seed gums which have never been used in the encapsulation process of phenolic compounds. Therefore, in this research, the effect of the nanoencapsulation process on biological properties of potato (Ramus variety) skin was evaluated. First, formation of W/O/W using by Salvia macrosiphon seed gum (SMSG) and Lepidium sativum Linn. seed gum (LSSG), individually or in combination (1:1) of SMSG and LSSG (CSL), was evaluated. Finally, the effect of $1000 \mathrm{ppm}$ of the nanoencapsulated extract on oxidative stability of soybean oil was investigated and compared with that of free extract and TBHQ.

\section{Materials and Methods}

2.1. Materials. The Ramus potato variety (Solanum tuberosum L. cultivar Ramus) was collected from Esfahan city (summer of 2019). Seeds of Salvia macrosiphon and Lepidium sativum Linn. were purchased from Tabibdaru Company in Shiraz city (summer of 2019). Soybean and sunflower antioxidant-free oils were prepared from Narges Shiraz oil Company (Shiraz, Fars Province, Iran). All the chemicals and solvents used were of analytical reagent grade and supplied by Merck and Sigma-Aldrich chemical companies (Darmstadt, Germany).

2.2. Extraction Process. The potato was peeled manually (1 mm depth). The skin was dried at $45^{\circ} \mathrm{C}$ for $24 \mathrm{~h}$ and then powdered by the aid of a grinder (Mullinex Depose-Brevete S.G.C.G.). About $35 \mathrm{~g}$ of the dried powder was mixed with $350 \mathrm{~mL}$ water-ethanol solvent (5-1), and the sample containing Erlens were then sonicated in an ultrasonic bath (DT $102 \mathrm{H}$; BANDELIN) $(35 \mathrm{kHz})$ for $20 \mathrm{~min}$ at $50^{\circ} \mathrm{C}[12]$.
2.3. Extraction of Seed Gums of Salvia macrosiphon and Lepidium sativum Linn. Seed gum of Salvia macrosiphon was extracted at optimum condition (water-to-seed ratio of $51: 1, \mathrm{pH}=5.5$, and temperature of $25^{\circ} \mathrm{C}$ ) as explained by Bostan et al. [18]. Seed gum of Lepidium sativum Linn. was extracted according to Karazhiyan et al. at optimum condition (water-to-seed ratio of $30: 1$, extraction time of $15 \mathrm{~m}$, $\mathrm{pH}=10$, and temperature of $35^{\circ} \mathrm{C}$ ) [19].

2.4. Biopolymer Solution Preparation. Gums of Salvia macrosiphon and Lepidium sativum Linn. were used as coating agents individually or in combination with a ratio of $1: 1$. The gums were dissolved in deionized water to reach a total solid material of $0.5 \%(\mathrm{~W} / \mathrm{W})$. Magnetic stirring was used for better dissolving (15 $\mathrm{min})$. The solvents were kept in the refrigerator for $24 \mathrm{~h}[12,15]$.

2.5. Preparation of $W / O / W$ Double Emulsions. The $\mathrm{W} / \mathrm{O} / \mathrm{W}$ two-layer nanoemulsions were prepared using two emulsion-forming steps. First of all, W/O microemulsion was prepared by dropwise addition of $7 \%$ potato skin extract in a continuous phase containing $25 \%$ span 80 and $68 \%$ soybean oil without antioxidant. In the second phase of emulsification, W/O initial microemulsion was coated with biopolymers prepared to produce $\mathrm{W} / \mathrm{O} / \mathrm{W}$ double emulsions. As a result, 30\% initial W/O emulsion was added to $70 \%$ prepared bipolymers and homogenized at $10^{\circ} \mathrm{C}$ for 5 minutes at $13709 \mathrm{~g}(12000 \mathrm{rpm})$ and then at $30845 \mathrm{~g}$ (18000 rpm) for 8 minutes. Then, the homogenizer (Avestin EmulsiFlex C3, ATA, USA) was used at a pressure of 11000 psi in 3, 5, and 7 cycles (90 seconds each) to reduce the particle size and to better stabilize the emulsion $[10,20]$.

2.6. Particle Size Measurement. Average particle size (Z-average), polydispersity index (PDI), and particle distribution were measured using a dynamic light scattering instrument (DLS) at $25^{\circ} \mathrm{C}$. The samples were diluted by 100 times using deionized water to prevent multiple scattering $[12,17]$.

2.7. $\zeta$-Potential. The $\zeta$-potential of emulsions was measured based on their electrophoretic mobility by a combination of laser Doppler velocimetry and phase analysis light scattering technique (Zetasizer Nano ZS, Malvern Instrument, England). Samples were diluted in deionized water at a ratio of $1: 100(\mathrm{v} / \mathrm{v})$ to avoid multiple scattering $[10,12]$.

2.8. Freeze-Drying of Nanoemulsions. Prepared nanoemulsions were frozen for 24 hours at $-50^{\circ} \mathrm{C}$ and then lyophilized in a freeze dryer (Martin Christ, 8891, type 317, Germany) at $P=0.09$ mbar and $T=0.01^{\circ} \mathrm{C}$ for 48 hours. The freeze-dried encapsulated samples were converted into powder with the help of a pestle and mortar [17].

2.9. Encapsulation Efficiency. $0.5 \mathrm{~g}$ of nanocoated powder was mixed with a volume of $2 \mathrm{~mL}$ ethanol-methanol solvent $(1: 1)$ and vortexed for $2 \mathrm{~min}$. The obtained mixture was 
passed through Watman filter paper no 1. Phenolic compounds' content was determined according to the Folin-Ciocalteau method. In this regard, encapsulation efficiency was estimated by the following equation:

$$
\text { Encapsulation efficiency }(\%)=100-\left(\frac{\mathrm{P} 2}{\mathrm{P} 1} \times 100\right) \text {, }
$$

where $P_{2}$ is the surface phenolic compounds and $P_{1}$ is the theoretical total polyphenol content [21].

2.10. Release Kinetics. The stability of nanocoatings was measured based on the release of phenolic compounds from $\mathrm{W} / \mathrm{O} / \mathrm{W}$ nanoemulsions. About $12 \mathrm{~g}$ of nanoencapsulated samples was poured in sealed dark glass containers. Then they were kept for 6 weeks at $30^{\circ} \mathrm{C}$, and at the end of each week, the content of superficial phenolic compounds was determined as described by Robert et al. Velocity constant $(k)$ and half-life time $\left(t_{1 / 2}\right)$ were determined based on the semilogarithmic graph slope according to polyphenolic compounds remaining within the microcapsules during storage. Half-life time of polyphenolic compounds, expressed as a $50 \%$ reduction of their initial values in the capsule, was estimated based on the curve slope and according to the formula $t_{1 / 2}=0.693 / k[21,22]$.

2.11. Total Phenolic Content. In order to measure the total phenolic content of different extracts and oil samples, a previously described method was used $[17,23]$. The estimation of phenolic compounds was performed at $765 \mathrm{~nm}$ using a UV-Vis spectrophotometer (Model 160A, Shimadzu, Japan) and calculated by a calibration curve $(R 2=0.99)$ performed with gallic acid (0 to $0.4 \mathrm{mg} / \mathrm{mL}$ ).

2.12. Oxidative Stability Index. A method as described previously was applied for determining the Oxidative Stability Index (OSI) by using a Rancimat (Metrohm Rancimat, model 743, Herisau, Switzerland) [5].

2.13. Peroxide Value and Thiobarbituric Acid Value. The peroxide value was measured according to the spectrophotometric method described by Tavakoli et al. [5]. Results were expressed in milliequivalents of peroxide per kilogram of oil. thiobarbituric acid value of the different oil samples was calculated based on the method ascribed by Cao et al. [24]. The basic principle of this method is the reaction of one molecule of malonaldehyde with two molecules of thiobarbituric acid to form a red-coloured malonaldehyde-TBA complex.

2.14. Statistical Analysis. All experiments were conducted in three replications, and the obtained results were analyzed by analysis of variance (ANOVA) (MStatC). Moreover, the Slide Write and Excel software were employed to design regression and graphs, respectively. Meanwhile, Duncan's test was applied to compare the mean values.

\section{Results and Discussion}

\subsection{Evaluation of Nanoemulsions}

3.1.1. The Size Distribution of Emulsion Drops and $\zeta$-Potential. Size distribution and PDI of multiple emulsions with SMSG, LSSG, and CSL were measured using the DLS method under diluted condition. The $\mathrm{z}$-average size is considered as the most stable and important parameter determined by DLS [25]. Pressure from 8000 to 14000 psi was used to reduce droplet size and homogenization. Pressure up to 11000psi reduced droplet size, while higher pressure caused coagulation and increased size of the drops. Thus, the pressure of 11000psi was used as an optimum pressure for emulsion homogenization at 3, 5, 7, and 10 time intervals (90s for each cycle). Similar studies have also reported that by exceeding homogenizing pressure from a certain threshold, emulsion droplets; size is increased $[26,27]$. The Z-average diameter of $\mathrm{W} / \mathrm{O} / \mathrm{W}$ formed by wall material is represented in Table 1 . The lowest $\mathrm{Z}$-average diameter was seen for CSL $(115.2 \mathrm{~nm})$ in the $7^{\text {th }}$ cycle, followed by LSSG (144.3 $\mathrm{nm}$ at the $7^{\text {th }}$ cycle) and SMSG $\left(160.2 \mathrm{~nm}\right.$ in the $5^{\text {th }}$ cycle). The difference is due to various emulsifying properties of these two materials such as surface activity, superficial absorption at the droplet surface, ductility characteristics, and intramolecular interaction in the contact point of water and oil [12].

In a similar study, Estakhr et al. [12] indicated that the Z-average size of emulsions coated by chitosan, locust bean gum, and the complex of chitosan and locust bean gum $(1: 1)$ was $115.47,128.37$, and $68.12 \mathrm{~nm}$, respectively. Also, in the present study, it was found that the combined use of different coatings caused the best emulsion size. The lowest $\mathrm{Z}$-average diameter of multiple emulsions formed by complex whey protein isolate-basil seed gum, Hi-Cap 100, and soy protein isolate-basil seed was $318 \mathrm{~nm}$ in cycle 10 , $736.9 \mathrm{~nm}$ in cycle 3 , and $1918 \mathrm{~nm}$ in cycle 5 . Moreover, it was observed that, in pressures higher than $12000 \mathrm{psi}$, the $\mathrm{Z}$-average size was increased which is due to protein degradation and reaggregation [17].

The droplet size distribution curve under high-pressure homogenizing condition based on the intensity parameter is presented in Figure 1. Information regarding the $\mathrm{Z}$-average size of droplet emulsions is only physical, while more accurate results can be obtained by knowing intensity distribution $[12,17]$. The best dispersion of emulsions coated with SMSG, LSSG, and CSL was achieved in times of 5, 7, and 7; so, intensity curves of them had only one peak in 250, 350, and $290 \mathrm{~nm}$ showing homogeneity of droplet size distribution. Lower width of these curves shows the lower distance of the droplet and smaller diameter size range. This represents a major index in determining emulsions' stability $[12,16]$. According to Figure 1, emulsion formed by CSL was the best one since it had the narrowest curve and hence higher homogeneity. It has been reported in some studies that emulsions with combined coat had larger droplets than those with monolayer coat $[10,17]$, while the inverse model was observed in the present study; that is, combined coat (CSL) caused the smallest droplets which can be attributed to 
TABLE 1: Particle size, polydispersity index (PDI), and zeta potential of W/O/W double emulsions stabilized by different wall materials at four time cycles.

\begin{tabular}{lccccccccc}
\hline Sample & \multicolumn{4}{c}{ Particle size $(\mathrm{nm})$} & \multicolumn{3}{c}{ PDI } & \multicolumn{2}{c}{$\begin{array}{c}\zeta \text {-potential } \\
(\mathrm{mV})\end{array}$} \\
& 3 & 5 & 7 & 10 & 3 & 5 & 7 & -18.4 \\
SMSG & 164.4 & 160.2 & 169.2 & 178.2 & 0.1009 & 0.0996 & 0.1132 & 0.1198 & -10 \\
LSSG & 165.2 & 161.5 & 144.3 & 179.9 & 0.1123 & 0.1016 & 0.1002 & 0.1112 & -18 \\
CSL & 130.1 & 147.8 & 115.2 & 159.3 & 0.082 & 0.079 & 0.072 & 0.091 & -16.7 \\
\hline
\end{tabular}

SMSG, Salvia macrosiphon Seed Gum; LSSG, Lepidium sativum Linn. Seed Gum; CSL, complex of SMSG and LSSG (1:1).

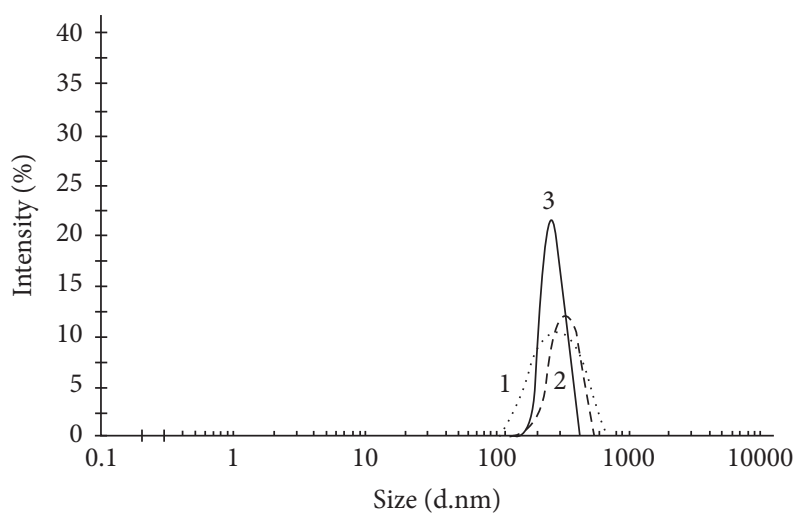

FIGURe 1: Particle size distribution of W/O/W emulsions of SMSG (1), LSSG (2), and mix (3). SMSG, Salvia macrosiphon Seed Gum; LSSG, Lepidium sativum Linn. Seed Gum; and CSL, complex of SMSG and LSSG $(1: 1)$.

the different behavior of biopolymers to the reduction of particle size. A study about nanoemulsification of Ferula persica polyphenolic extract was conducted based on the intensity curve found that the combined use of chitosan and locust bean gum made the best conditions consistent with the results of the present study [12].

PDI shows homogeneity of dispersion whose value varies between 0 and 1. PDI close to zero indicates homogenous particle size, and values higher than 0.5 show particles with uneven size distribution [28]. As represented in Table 1, the PDI of nanoemulsions was lower than 0.2, indicating even size distribution and success of the nanoparticle generation process. The results of PDI accord with those of Z-average size and intensity distribution. In an investigation, the PDI of multiple emulsions formed by HiCap 100, complex whey protein isolate-basil seed gum, and soy protein isolate-basil seed has been reported below 0.3 (25) showing more successful nanoparticle generation in the present study. Also, in another study, the amount of PDI in nanoemulsions produced by chitosan, locust bean gum, and the complex of chitosan and locust bean gum was lower than 0.5 [12].

Like size distribution and PDI, $\zeta$-potential is a major factor for the evaluation of colloidal dispersion [28]. Colloid systems gain surface charge during ionization of functional groups or due to superficial absorption of the ions available in the medium. Electrostatic repulsion of surface charge of nanoparticles prevents particles' aggregation and, hence, improves system stability. $\zeta$-Potential is the index of surface charge that controls emulsion droplet interaction and produces stability through the system [29]. $\zeta$-potential of emulsion particles coated with SMSG, LSSG, and CSL was $-18.4,-18$, and $-16.7 \mathrm{~m}$ (Table 1). The negative sign of $\zeta$-potential is due to the anionic nature of both gums used for wall coating. A part of this charge can be due to the joining of a part of polyphenols. In previous studies, it has been reported that if $\zeta$-potential of emulsion particles is between -30 and +30 , they are stable through the time [30]. Sadeghi et al. [17] observed the lowest $\zeta$-potential of $-13.1 \mathrm{mV}$ for emulsion droplets coated with Hi-Cap 100 while the highest value for emulsion droplets coated with complex whey protein isolate-basil seed gum and soy protein isolate-basil seed was -29.2 and $-30.3 \mathrm{mV}$; respectively. Estakhr et al. [12], in a study, evaluated the characteristics of multilayered nanomolecules of Ferula persica extract. The $\zeta$-potential for samples coated with chitosan, locust bean gum, and the complex of chitosan and locust bean was $25.97,-9.2$, and -41.05 , respectively. As it turned out, the amount of this factor in locust bean gum, like the two gums studied in the present investigation, was negative.

3.1.2. Encapsulation Efficiency and Release Properties. Coating of antioxidant compounds by bilayer $\mathrm{W} / \mathrm{O} / \mathrm{W}$ nanoemulsions increases their solubility and stability; so, the release of polyphenolic compounds from nanoencapsulations has a significant impact on continuance of their antioxidant power [31]. In this study, encapsulation efficiency and release of polyphenols from the aqueous phase of bilayer emulsions during 40 days of storage at $30^{\circ} \mathrm{C}$ were measured by determining total polyphenols. The initial encapsulation efficiency of powders encapsulated by SMSG, LSSG, and CSL was $82.39 \%, 81.67 \%$, and $93.6 \%$ (Table 2) showing that the application of the two gums increased this index. In a similar research, Estakhr et al. [12] indicated that the amount of this factor in powder encapsulated with chitosan and locust bean gum was between 85.3 and $93.3 \%$. The amount of initial encapsulation in the sample that was used in combination was the highest value and was close to CSL. Sadeghi et al. [17] reported that initial encapsulation efficiency of powder encapsulated with Hi-Cap 100, complex whey protein isolate-basil seed gum and soy protein isolatebasil seed was between $90.9 \%$ and $92.88 \%$; showing no significant difference. Moreover, 40 days of storage at $30^{\circ} \mathrm{C}$ showed that the lowest reduction of encapsulation efficiency occurred in the powder encapsulated with CSL (33.05\%); followed by LSSG (40.95\%) and SMSG (45.04\%). It has been reported in previous studies that the reduced size of droplets enhances their stability and encapsulation efficiency $[32,33]$ 
TABLE 2: Encapsulation efficiency, regression analysis, and half-life values of encapsulated powders produced with different wall materials during 40 days storage at $30^{\circ} \mathrm{C}$.

\begin{tabular}{|c|c|c|c|c|c|c|c|c|}
\hline \multirow{2}{*}{ Sample } & \multicolumn{5}{|c|}{ Storage time (days) } & \multicolumn{3}{|c|}{ Parameters } \\
\hline & 8 & 16 & 24 & 32 & 40 & $\mathrm{~K}\left(\right.$ days $\left.^{-1}\right)$ & $t_{1 / 2}$ (days) & $R_{2}$ \\
\hline SMSG & $82.39 \pm 1.07^{\mathrm{b}}$ & $74.82 \pm 1.68^{\mathrm{b}}$ & $63.17 \pm 0.74^{\mathrm{b}}$ & $55.61 \pm 1.86^{\mathrm{b}}$ & $45.28 \pm 2^{\mathrm{b}}$ & 0.0187 & 37.05 & 0.99 \\
\hline LSSG & $81.67 \pm 1.53^{\mathrm{b}}$ & $77 \pm 1^{\mathrm{b}}$ & $65.67 \pm 2.52^{\mathrm{b}}$ & $55 \pm 1^{\mathrm{b}}$ & $48.22 \pm 1.2^{\mathrm{b}}$ & 0.0174 & 39.83 & 0.98 \\
\hline CSL & $93.6 \pm 1.2^{\mathrm{a}}$ & $85.27 \pm 0.64^{\mathrm{a}}$ & $78.97 \pm 0.95^{\mathrm{a}}$ & $69.8 \pm 1.93^{\mathrm{a}}$ & $62.67 \pm 1.6^{\mathrm{a}}$ & 0.0125 & 55.44 & 0.99 \\
\hline
\end{tabular}

SMSG, Salvia macrosiphon Seed Gum; LSSG Lepidium sativum Linn. Seed Gum; CSL, complex of SMSG and LSSG $(1: 1)$.

which accords with our findings. The highest and lowest value of encapsulation efficiency was observed in powders encapsulated with CSL and SMSG whose emulsions had the lowest and highest Z-average size. Rate constant $(k)$ and halflife period $\left({ }_{\mathrm{t} 1 / 2}\right)$ of the encapsulated powders are represented in Table 2 and Figure 2. CSL had the lowest rate constant (0.0125) and the highest half-life period (55.44 days). In a study, amount of rate constant and half-life period of encapsulated powders with locust bean gum was reported to be 0.0145 and 47.8 days, respectively [12]. These two parameters have been reported to be $0.0529,0.0563,0.0745$ and 13.1, 12.3, and 9.3 for Hi-Cap 100, complex whey protein isolatebasil seed gum, and soy protein isolate-basil seed, which shows the significant difference with the results obtained in the present research. This difference is attributed to the difference in coating materials [17].

\subsection{Effect of Nanoencapsulated Extracts on the Oxidative} Stability of Soybean Oil. Oxidative encapsulation of edible oils is commonly evaluated and controlled by intensified oxidative condition including temperature, oxygenation, and light because oxidation and change of oil require a long period [5]. In this research, the oxidative stability of edible oil was investigated at $50^{\circ} \mathrm{C}$ because higher temperatures impose the risk of peroxides' degradation. Peroxide, $\mathrm{p}$-anisidine, and OSI values were evaluated during 40-day storage to investigate oxidative stability.

3.2.1. Peroxide Value. Measurement of hydroperoxides is a common way for the evaluation of lipid oxidation progress. Hydroperoxides are the products of primary oxidation of lipids whose content during oxidation is increased at first and then decreased. These products are unstable and converted to aldehydes, ketones, alcohols, and so forth [4]. Peroxide values of various soybean oil samples are presented in Table 3. No significant difference was observed for the primary peroxide values of the samples. PV was increased during storage, and the value for pure soybean oil (control) samples containing $1000 \mathrm{ppm}$ free extract 2 and extract 2 encapsulated with SMSG, LSSG, and CSL and $1000 \mathrm{ppm}$ TBHQ was $170,137.5,130,124.5,121.25$, and 150.5 times the primary value. This shows that the addition of various samples had a positive impact on the oxidative stability of soybean oil. PS extract 2 encapsulated with CSL had the best antioxidant effect in soybean oil, followed by those encapsulated by LSSG, SMSG, free extract 2, and TBHQ. The superiority of nanoencapsulated phenolic extract of potato skin is a considerable finding of the present research which is

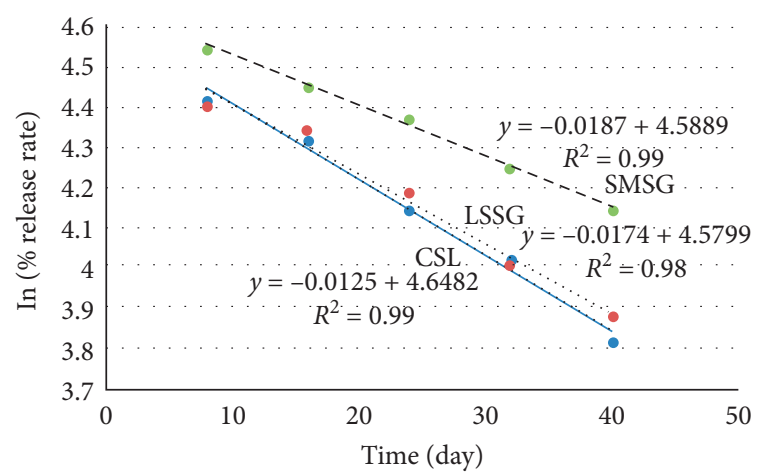

FIgURE 2: Release rate and regression equations of phenolic compounds of nanocapsules coated with of SMSG (1), LSSG (2), and mix (3). SMSG, Salvia macrosiphon Seed Gum; LSSG, Lepidium sativum Linn. Seed Gum; and CSL, complex of SMSG and LSSG $(1: 1)$.

in contrast with previous reports. In two studies, the Ferula persica and Mentha piperita nanocapsulated extracts had a higher resistance to the formation of hydroperoxides than TBHQ. It was also found that the extract covered with a combination of chitosan and gums was recognized as the best treatment, which was consistent with the results of the present study [12, 32]. Sadeghi et al. [17] reported that nanoencapsulated phenolic extract of Beneh skin had a better antioxidant effect compared to its free extract. Moreover, the antioxidant activity of these extracts was lower than that of TBHQ. This difference can be attributed to the concentration of phenolic compounds in the extracts. In the research conducted by Delfanian et al., the phenolic compounds' content varied between 100 and 300 ppm, and hence, the extracts had lower antioxidant power than TBHQ. However, in the present study, the phenolic compounds' content of the extracts was $1000 \mathrm{ppm}$ that can explain their superiority over TBHQ.

3.2.2. Thiobarbituric Acid Value. Peroxide value is not a suitable test for evaluating oil oxidation since this value is an index of primary oxidation products and does not measure secondary products of oxidation. Thus, it is necessary to conduct an assay such as the determination of thiobarbituric acid value (the content of malondialdehyde) that shows oxidation progress and generation of secondary products [34]. As presented in Table 3, the formation of secondary products during 40 -day storage at $50^{\circ} \mathrm{C}$ followed an increasing trend. There was no significant difference in the 
TABLE 3: Effect of adding free extract 2 and nanoencapsulated extract produced by SMSG, LSSG, and CSL at $1000 \mathrm{ppm}$ and TBHQ (100 ppm) on peroxide value, thiobarbituric acid value, and oil/oxidative stability index of soybean oil under accelerated storage at $50^{\circ} \mathrm{C}$ for 40 days.

\begin{tabular}{|c|c|c|c|c|c|c|}
\hline \multirow{3}{*}{ Time (days) } & \multirow{3}{*}{ Control } & \multicolumn{4}{|c|}{ Peroxide value } & \multirow{3}{*}{ TBHQ } \\
\hline & & $\mathrm{DSF}$ & \multicolumn{3}{|c|}{ Nanoencapsulated PSE produced by } & \\
\hline & & PSE & SMSG & LSSG & CSL & \\
\hline 0 & $0.5 \pm 0.05^{\mathrm{a}}$ & $0.4 \pm 0.03^{\mathrm{a}}$ & $0.4 \pm 0.03^{\mathrm{a}}$ & $0.4 \pm 0.05^{\mathrm{a}}$ & $0.4 \pm 0.06^{\mathrm{a}}$ & $0.5 \pm 0.03^{\mathrm{a}}$ \\
\hline 8 & $8 \pm 0.5^{\mathrm{a}}$ & $4 \pm 0.4^{\mathrm{c}}$ & $4 \pm 0.5^{\mathrm{c}}$ & $4 \pm 0.4^{\mathrm{c}}$ & $5 \pm 0.6^{\mathrm{C}}$ & $6 \pm 0.3^{b}$ \\
\hline 16 & $16 \pm 1^{\mathrm{a}}$ & $10 \pm 0.9^{c}$ & $9 \pm 0.7^{\mathcal{C}}$ & $9.6 \pm 0.4^{\mathrm{c}}$ & $9.1 \pm 0.5^{\mathrm{c}}$ & $11.7 \pm 0.7^{\mathrm{b}}$ \\
\hline 24 & $40 \pm 2.2^{\mathrm{a}}$ & $27 \pm 0.8^{\mathrm{c}}$ & $26 \pm 0.8^{\mathrm{c}}$ & $27 \pm 0.5^{\mathrm{c}}$ & $26.3 \pm 0.7^{\mathrm{c}}$ & $32 \pm 0.9^{\mathrm{b}}$ \\
\hline 32 & $72.5 \pm 1.2^{\mathrm{a}}$ & $45 \pm 1.5^{\mathrm{c}}$ & $42 \pm 1.2^{\mathrm{d}}$ & $41.5 \pm 1^{\mathrm{d}}$ & $40.7 \pm 1.3^{\mathrm{d}}$ & $48.9 \pm 1.5^{\mathrm{b}}$ \\
\hline 40 & $85 \pm 2.3^{\mathrm{a}}$ & $55 \pm 0.4^{\mathrm{c}}$ & $52 \pm 0.4^{\mathrm{d}}$ & $49.8 \pm 0.6^{\mathrm{e}}$ & $48.5 \pm 0.4^{\mathrm{f}}$ & $60.2 \pm 1.7^{\mathrm{b}}$ \\
\hline \multirow{3}{*}{ Time (days) } & \multicolumn{6}{|c|}{ Thiobarbituric acid value } \\
\hline & & & \multicolumn{3}{|c|}{ Nanoencapsulated PSE produced by } & \\
\hline & Cont & $s \mathrm{~B}$ & SMSG & LSSG & CSL & TBHQ \\
\hline 0 & $0.085 \pm 0.004^{\mathrm{a}}$ & $0.085 \pm 0.004^{\mathrm{a}}$ & $0.085 \pm 0.003^{\mathrm{a}}$ & $0.085 \pm 0.004^{\mathrm{a}}$ & $0.085 \pm 0.004^{\mathrm{a}}$ & $0.085 \pm 0.004^{\mathrm{a}}$ \\
\hline 8 & $0.095 \pm 0.005^{\mathrm{a}}$ & $0.092 \pm 0.004^{\mathrm{a}}$ & $0.091 \pm 0.003^{\mathrm{a}}$ & $0.098 \pm 0.004^{\mathrm{a}}$ & $0.099 \pm 0.006^{\mathrm{a}}$ & $0.094 \pm 0.003^{\mathrm{a}}$ \\
\hline 16 & $0.201 \pm 0.006^{\mathrm{b}}$ & $0.175 \pm 0.005^{\mathrm{d}}$ & $0.194 \pm 0.004^{c}$ & $0.206 \pm 0.006^{\mathrm{b}}$ & $0.216 \pm 0.007^{\mathrm{a}}$ & $0.194 \pm 0.005^{\mathrm{c}}$ \\
\hline 24 & $0.865 \pm 0.004^{\mathrm{a}}$ & $0.458 \pm 0.005^{\mathrm{cd}}$ & $0.464 \pm 0.007^{\mathrm{c}}$ & $0.448 \pm 0.007^{\mathrm{e}}$ & $0.451 \pm 0.005^{\mathrm{d}}$ & $0.511 \pm 0.008^{\mathrm{b}}$ \\
\hline 32 & $1.347 \pm 0.007^{\mathrm{a}}$ & $0.752 \pm 0.005^{\mathrm{c}}$ & $0.702 \pm 0.008^{\mathrm{d}}$ & $0.667 \pm 0.005^{\mathrm{e}}$ & $0.630 \pm 0.007^{\mathrm{f}}$ & $0.790 \pm 0.007^{\mathrm{b}}$ \\
\hline 40 & $1.614 \pm 0.005^{\mathrm{a}}$ & $0.962 \pm 0.007^{\mathrm{b}}$ & $0.830 \pm 0.008^{\mathrm{d}}$ & $0.802 \pm 0.007^{\mathrm{e}}$ & $0.768 \pm 0.007^{\mathrm{f}}$ & $0.808 \pm 0.006^{\mathrm{c}}$ \\
\hline \multicolumn{7}{|c|}{ Oil/oxidative stability index } \\
\hline \multirow{2}{*}{ Time (days) } & \multirow{2}{*}{ Control } & \multirow{2}{*}{ PSE } & \multicolumn{3}{|c|}{ Nanoencapsulated PSE produced by } & TBHQ \\
\hline & & & SMSG & LSSG & CSL & \\
\hline 0 & $3.23 \pm 0.04^{\mathrm{d}}$ & $3.47 \pm 0.04^{\mathrm{b}}$ & $3.19 \pm 0.05^{\mathrm{d}}$ & $3.36 \pm 0.07^{\mathrm{c}}$ & $3.43 \pm 0.05^{b c}$ & $3.97 \pm 0.04^{\mathrm{a}}$ \\
\hline 8 & $2.95 \pm 0.04^{\mathrm{d}}$ & $3.13 \pm 0.05^{\mathrm{c}}$ & $2.97 \pm 0.03^{\mathrm{d}}$ & $3.23 \pm 0.04^{\mathrm{b}}$ & $3.29 \pm 0.04^{\mathrm{b}}$ & $3.74 \pm 0.05^{\mathrm{a}}$ \\
\hline 16 & $2.6 \pm 0.04^{\mathrm{d}}$ & $3.09 \pm 0.05^{\mathrm{b}}$ & $2.79 \pm 0.04^{\mathrm{c}}$ & $3.03 \pm 0.03^{\mathrm{b}}$ & $3.1 \pm 0.04^{\mathrm{b}}$ & $3.32 \pm 0.04^{\mathrm{a}}$ \\
\hline 24 & $1.92 \pm 0.04^{\mathrm{e}}$ & $2.48 \pm 0.05^{\mathrm{d}}$ & $2.6 \pm 0.03^{c}$ & $2.69 \pm 0.04^{\mathrm{b}}$ & $2.77 \pm 0.05^{\mathrm{b}}$ & $2.95 \pm 0.05^{\mathrm{a}}$ \\
\hline 32 & $2.09 \pm 0.02^{\mathrm{e}}$ & $2.16 \pm 0.03^{\mathrm{d}}$ & $2.22 \pm 0.04^{c}$ & $2.23 \pm 0.04^{\mathrm{c}}$ & $2.33 \pm 0.03^{\mathrm{b}}$ & $2.48 \pm 0.05^{\mathrm{a}}$ \\
\hline 40 & $1.15 \pm 0.02^{\mathrm{d}}$ & $1.07 \pm 0.03^{\mathrm{e}}$ & $1.18 \pm 0.02^{\mathrm{c}}$ & $1.23 \pm 0.04^{\mathrm{c}}$ & $1.33 \pm 0.03^{\mathrm{b}}$ & $1.42 \pm 0.02^{\mathrm{a}}$ \\
\hline
\end{tabular}

Extract 2, water-ethanol extract of potato skin treated with ultrasonic waves; SMSG, Salvia macrosiphon Seed Gum; LSSG, Lepidium sativum Linn. Seed Gum; CSL, complex of SMSG and LSSG $(1: 1)$.

primary thiobarbituric acid value of the samples. It was also found that, after 40 days of storage period at $50^{\circ} \mathrm{C}$, the final amount of this parameter for pure soybean oil (control) samples containing $1000 \mathrm{ppm}$ free extract 2 and extract 2 encapsulated with SMSG, LSSG, and CSL and $100 \mathrm{ppm}$ TBHQ was $1799,1302,877,844,804$, and 851 times the primary value. As seen, the addition of all antioxidant samples had a positive impact on the oxidative stability of soybean oil. The extract 2 encapsulated with CSL had the best antioxidant effect in soybean oil, followed by those encapsulated by LSSG, SMSG, TBHQ, and free extract 2. As was the case for PV, nanoencapsulation of the extracts increased the oxidative stability of soybean oil. It has been reported in similar studies that nanoencapsulated extract of Beneh skin, Ferula persica, and Mentha piperita had better antioxidant effect compared to its free extract $[12,17,32]$.

3.2.3. Rancimat Assay. The OSI value of different oil samples is presented in Table 3 showing that OSI of pure soybean oil (control) samples containing 1000 ppm free extract 2 and extract 2 encapsulated with SMSG, LSSG, and CSL and 100 ppm TBHQ at the initial time was 3.23, 3.47, 3.19, 3.36, 3.43 , and $3.97 \mathrm{~h}$. The corresponding values at the end of storage were reduced to $1.15,1.07,1.18,1.23,1.33$, and $1.42 \mathrm{~h}$. Soybean oil containing TBHQ was the best sample in this assay; followed by those containing extract 2 encapsulated with CSL, LSSG and SMSG, pure oil, and oil containing free extract 2 . In contrast to previous tests, TBHQ had the best antioxidant impact that can be attributed to rancimat assay which was performed at $120^{\circ} \mathrm{C}$. In general, TBHQ shows a better antioxidant effect at higher temperatures. Moreover, it was observed that the application of different coatings on nanoencapsulated extract provided better oxidative stability compared to free extract 2 . The Rencimet test is used as a complementary experiment, in addition to other oxidative stability tests. It is also used to identify the antioxidant effect of vegetable oils and their extracts. In two different studies, Pistacia khinjuk fruit oil and its unsaponifiable matters were used to affect the oxidative stability of olive oil. The results showed that Pistacia khinjuk fruit oil and its unsaponifiable matters had similar effects to TBHQ in a concentration of $0.5 \%$ and $100 \mathrm{ppm}$ at $170^{\circ} \mathrm{C}$, respectively $[5,7]$.

3.3. Phenolic Compound Release. The results of peroxide value, thiobarbituric acid, and OSI indicated that the application of coating substances for encapsulation increased their antioxidant effect compared to TBHQ and extract 2. For better evaluation of their performance, the release of phenolic compounds from encapsulated extracts into soybean oil was measured through determining total phenolic compounds. As represented in Table 4, the release of phenolic compounds was faster in the extracts encapsulated with SMSG and LSSG compared to that encapsulated with 
TABLE 4: The release rate of phenolic compounds $(\mathrm{mg} / \mathrm{kg})$ in oil from encapsulated powders produced by SMSG, LSSG, and CSL at levels of $1000 \mathrm{ppm}$.

\begin{tabular}{lccc}
\hline Time (days) & SMSG & LSSG & CSL \\
\hline 8 & $89 \pm 5.3^{\mathrm{a}}$ & $87 \pm 4.3^{\mathrm{a}}$ & $75 \pm 3.9^{\mathrm{b}}$ \\
16 & $149 \pm 8.1^{\mathrm{a}}$ & $139 \pm 5.1^{\mathrm{a}}$ & $137 \pm 5.2^{\mathrm{a}}$ \\
24 & $212 \pm 10.3^{\mathrm{a}}$ & $209 \pm 5.6^{\mathrm{a}}$ & $165 \pm 6.7^{\mathrm{b}}$ \\
32 & $244 \pm 9.7^{\mathrm{a}}$ & $238 \pm 8.2^{\mathrm{a}}$ & $200 \pm 9.2^{\mathrm{b}}$ \\
40 & $283 \pm 5.7^{\mathrm{a}}$ & $286 \pm 6.5^{\mathrm{a}}$ & $237 \pm 8^{\mathrm{a}}$ \\
\hline
\end{tabular}

SMSG, Salvia macrosiphon Seed Gum; LSSG, Lepidium sativum Linn. Seed Gum; CSL, complex of SMSG and LSSG $(1: 1)$.

CSL; hence, more phenolic compounds entered the oil. The combined coating had higher resistance to phenolic compounds release. However, CSL had the best performance in oxidative stability assays. This can be due to the creation of peroxidation condition as a result of the extra increase of phenolic compounds as antioxidant agents in the sample containing extract 2 nanoencapsulated with LSSG and SMSG. Moreover, since phenolic compound release in extract 2 nanoencapsulated with CSL was more gradual, it lengthens soybean oil storage time. Previous studies have implied that the application of encapsulated phenolic extract had better performance compared to free extract [35]. Sadeghi et al. [17] reported that the content of phenolics released from Beneh skin encapsulated was too small to delay oxidation of soybean oil. This observation was due to the small amount of phenolics in the extracts (100-300 ppm) which bears different results. Phenolic compound content in the present study was 3.3 to 10 times more than those observed in the aforementioned study and, hence, significantly delayed oxidation of soybean oil. In the other study, it was reported that the highest phenolic compounds were released in soybean oil containing Ferula persica extract nanoencapsulated with a complex of chitosan and locust bean gum $(1: 1)$, followed by extract samples with locust bean gum and chitosan. It was also found that the reason for the superiority of this treatment in oxidative stability tests was related to the release of more phenolic compounds in soybean oil [12].

\section{Conclusions}

In this research, first, the potato skin extract was used to make nanoemulsions with different coatings (SMSG, LSSG, and CSL). Measurement of zeta potential, polydispersity index (PDI), particle size, and encapsulation efficiency revealed that $\mathrm{W} / \mathrm{O} / \mathrm{W}$ of nanoemulsions created by CSL was the best treatment, followed by LSSG and SMSG with a slight difference. The superiority of CSL can be due to the positive impact of the application of two gums. Moreover, it was observed that the extract encapsulated with CSL had the best antioxidant effect on soybean oil, followed by those encapsulated with LSSG and SMSG. Phenolic compound release from encapsulated extracts into soybean oil during storage indicated that combined coating had higher resistance to phenolic compound release and a lower amount of phenolics fluxed into the oil. Moreover, since phenolic compound release in the extract nanoencapsulated with CSL was more gradual, it lengthens soybean oil storage time. Furthermore, the application of the extract nanoencapsulated with CSL in other types of oil can be investigated.

\section{Data Availability}

The data used to support the study are included within the article. Raw data can be acquired from the corresponding author upon reasonable request.

\section{Conflicts of Interest}

The authors declare no conflicts of interest.

\section{Acknowledgments}

The authors would like to thank the Jundi-Shapur University of Technology (Project no. 98-2-395-02) for the financial support for this work.

\section{References}

[1] M. Gavahian, Y. H. Chu, and A. Mousavi Khaneghah, "Recent advances in orange oil extraction: an opportunity for the valorisation of orange peel waste a review," International Journal of Food Science \& Technology, vol. 54, no. 4, pp. 925-932, 2019.

[2] J. Singh and L. Kaur, Advances in Potato Chemistry and Technology, Elsevier applied science, London, England, 2nd edition, 2016.

[3] T. Albishi, J. A. John, A. S. Al-Khalifa, and F. Shahidi, "Phenolic content and antioxidant activities of selected potato varieties and their processing by-products," Journal of Functional Foods, vol. 5, no. 2, pp. 590-600, 2013.

[4] N. T. Dunford, "Oxidative stability of sunflower seed oil," in Sunflower: Chemistry, Production, Processing, and Utilization, E. Martnez-Force", N. T. Dunford, and J. J. Salas, Eds., pp. 465-489, AOCS Press, Urbana, IL, USA, 2015.

[5] J. Tavakoli, T. Emadi, S. M. B. Hashemi et al., "Chemical properties and oxidative stability of Arjan (Amygdalus reuteri) kernel oil as emerging edible oil," Food Research International, vol. 107, pp. 378-384, 2018.

[6] A. A. A. Mohdaly, M. A. Sarhan, A. Mahmoud, M. F. Ramadan, and I. Smetanska, "Antioxidant efficacy of potato peels and sugar beet pulp extracts in vegetable oils protection," Food Chemistry, vol. 123, no. 4, pp. 1019-1026, 2010.

[7] J. Tavakoli, M. S. Brewer, A. Zarei Jelyani, and P. Estakhr, "Oxidative stability of olive oil during the thermal process: effect of Pistacia khinjuk fruit oil," International Journal of Food Properties, vol. 20, no. 12, pp. 3256-3265, 2017.

[8] S. M. B. Hashemi, A. Mousavi Khaneghah, M. Koubaa et al., "Extraction of essential oil from Aloysia citriodora Palau leaves using continuous and pulsed ultrasound: kinetics, antioxidant activity and antimicrobial properties," Process Biochemistry, vol. 65, pp. 197-204, 2018.

[9] J. M. Lorenzo, A. Mousavi Khaneghah, M. Gavahian et al., "Understanding the potential benefits of thyme and its derived products for food industry and consumer health: from extraction of value-added compounds to the evaluation of bioaccessibility, bioavailability, anti-inflammatory, and 
antimicrobial activities," Critical Reviews in Food Science and Nutrition, vol. 59, pp. 2579-2595, 2018.

[10] A. Mohammadi, S. M. Jafari, E. Assadpour, and A. Faridi Esfanjani, "Nano-encapsulation of olive leaf phenolic compounds through WPC-pectin complexes and evaluating their release rate," International Journal of Biological Macromolecules, vol. 82, pp. 816-822, 2016.

[11] H. C. F. Carneiro, R. V. Tonon, C. R. F. Grosso, and M. D. Hubinger, "Encapsulation efficiency and oxidative stability of flaxseed oil microencapsulated by spray drying using different combinations of wall materials," Journal of Food Engineering, vol. 115, no. 4, pp. 443-451, 2013.

[12] P. Estakhr, J. Tavakoli, F. Beigmohammadi, S. Alaei, and A. Mousavi Khaneghah, "Incorporation of the nanoencapsulated polyphenolic extract of Ferula persica into soybean oil: assessment of oil oxidative stability," Food Science and. Nutrition, vol. 8, pp. 2717-2826, 2020.

[13] P. N. Ezhilarasi, P. Karthik, N. Chhanwal, and C. Anandharamakrishnan, "Nanoencapsulation techniques for food bioactive components: a review," Food and Bioprocess Technology, vol. 6, no. 3, pp. 628-647, 2013.

[14] M. R. Mozafari, J. Flanagan, L. Matia-Merino et al., "Recent trends in the lipid-based nanoencapsulation of antioxidants and their role in foods," Journal of the Science of Food and Agriculture, vol. 86, no. 13, pp. 2038-2045, 2006.

[15] M. Delfanian, S. M. A. Razavi, M. H. Haddad Khodaparast, R. Esmaeilzadeh Kenari, and S. Golmohammadzadeh, "Influence of main emulsion components on the physicochemical and functional properties of $\mathrm{W} / \mathrm{O} / \mathrm{W}$ nanoemulsion: effect of polyphenols, Hi-Cap, basil seed gum, soy and whey protein isolates," Food Research International, vol. 108, pp. 136-143, 2018.

[16] G. Davidov-Pardo and D. J. McClements, "Nutraceutical delivery systems: resveratrol encapsulation in grape seed oil nanoemulsions formed by spontaneous emulsification," Food Chemistry, vol. 167, pp. 205-212, 2015.

[17] S. Sadeghi, A. Madadlou, and M. Yarmand, "Microemulsification-Cold gelation of whey proteins for nanoencapsulation of date palm pit extract," Food Hydrocolloids, vol. 35, pp. 90-596, 2014.

[18] A. Bostan, S. M. A. Razavi, and R. Farhoosh, "Optimization of hydrocolloid extraction from wild sage seed (Salvia macrosiphon) using response surface," International Journal of Food Properties, vol. 13, no. 6, pp. 1380-1392, 2010.

[19] H. Karazhiyan, S. M. A. Razavi, and G. O. Phillips, "Extraction optimization of a hydrocolloid extract from cress seed (Lepidium sativum) using response surface methodology," Food Hydrocolloids, vol. 25, no. 5, pp. 915-920, 2011.

[20] A. M. Hashtjin and S. Abbasi, "Nano-emulsification of orange peel essential oil using sonication and native gums," Food Hydrocolloids, vol. 44, pp. 40-48, 2015.

[21] P. Robert, T. Gorena, N. Romero, E. Sepulveda, J. Chavez, and C. Saenz, "Encapsulation of polyphenols and anthocyanins from pomegranate (Punica granatum) by spray drying," International Journal of Food Science \& Technology, vol. 45, no. 7, pp. 1386-1394, 2010.

[22] M. N. Najafi, R. Kadkhodaee, and S. A. Mortazavi, "Effect of drying process and wall material on the properties of encapsulated cardamom oil," Food Biophysics, vol. 6, pp. 68-76, 2011.

[23] J. Tavakolli, N. Sedaghat, and A. Mousavi Khaneghah, "Effects of packaging and storage conditions on Iranian wild pistachio kernels and assessment of oxidative stability of edible extracted oil," Journal of Food Processing and Preservation, vol. 43, pp. 1-10, 2019.

[24] J. Cao, H. Li, X. Xia et al., "Effect of fatty acid and tocopherol on oxidative stability of vegetable oils with limited air," International Journal of Food Properties, vol. 18, no. 4, pp. 808-820, 2015.

[25] A. Bryła, G. Lewandowicz, and W. Juzwa, "Encapsulation of elderberry extract into phospholipid nanoparticles," Journal of Food Engineering, vol. 167, pp. 189-195, 2015.

[26] G. Kolb, K. Viardot, G. Wagner, and J. Ulrich, "Evaluation of a new high-pressure dispersion unit (HPN) for emulsification," Chemical Engineering \& Technology, vol. 24, no. 3, pp. 293296, 2001.

[27] P. Marie, J. M. Perrier-Cornet, and P. Gervais, "Influence of major parameters in emulsification mechanisms using a highpressure jet," Journal of Food Engineering, vol. 53, no. 1, pp. 43-51, 2002.

[28] R. Lutz, A. Aserin, L. Wicker, and N. Garti, "Release of electrolytes from $\mathrm{W} / \mathrm{O} / \mathrm{W}$ double emulsions stabilized by a soluble complex of modified pectin and whey protein isolate," Colloids and Surfaces B: Biointerfaces, vol. 74, no. 1, pp. 178-185, 2009.

[29] J. Rao and D. J. McClements, "Food-grade microemulsions and nanoemulsions: role of oil phase composition on formation and stability," Food Hydrocolloids, vol. 29, no. 2, pp. 326-334, 2012.

[30] A. Laouini, C. Jaafar-Maalej, S. Sfar, C. Charcosset, and H. Fessi, "Liposome preparation using a hollow fiber membrane contactor-Application to spironolactone encapsulation," International Journal of Pharmaceutics, vol. 415, no. 1-2, pp. 53-61, 2011.

[31] Z. Li, H. Jiang, C. Xu, and L. Gu, "A review: using nanoparticles to enhance absorption and bioavailability of phenolic phytochemicals," Food Hydrocolloids, vol. 43, pp. 153-164, 2015.

[32] S. Roshanpour, J. Tavakoli, F. Beigmohammadi, and S. Alaei, "Improving antioxidant effect of phenolic extract of Mentha piperita using nanoencapsulation process," Journal of Food Measurement and Characterization, vol. 15, no. 1, pp. 23-32, 2021.

[33] L. Salvia-Trujillo, E. A. Decker, and D. J. McClements, "Influence of an anionic polysaccharide on the physical and oxidative stability of omega-3 nanoemulsions: antioxidant effects of alginate," Food Hydrocolloids, vol. 52, pp. 690-698, 2016.

[34] Y. Zhang, L. Yang, Y. Zu, X. Chen, F. Wang, and F. Liu, "Oxidative stability of sunflower oil supplemented with carnosic acid compared with synthetic antioxidants during accelerated storage," Food Chemistry, vol. 118, no. 3, pp. 656-662, 2010.

[35] A. Belščak-Cvitanović, R. Stojanović, V. Manojlović et al., "Encapsulation of polyphenolic antioxidants from medicinal plant extracts in alginate-chitosan system enhanced with ascorbic acid by electrostatic extrusion," Food Research International, vol. 44, pp. 1094-1101, 2011. 